\title{
Article \\ Covalent Immobilisation of a Nanoporous Platinum Film onto a Gold Screen-Printed Electrode for Highly Stable and Selective Non-Enzymatic Glucose Sensing
}

\author{
Wesley McCormick ${ }^{1,2}\left(\mathbb{D}\right.$, Pádraig McDonagh ${ }^{2}\left(D\right.$, John Doran ${ }^{1,3}$ and Denis McCrudden ${ }^{1,2, *(1)}$ \\ 1 The Bryden Centre, Letterkenny Institute of Technology, F92 FC93 Letterkenny, Ireland; \\ L00006105@student.lyit.ie (W.M.); john.doran@lyit.ie (J.D.) \\ 2 Department of Life and Physical Sciences, Letterkenny Institute of Technology, F92 FC93 Letterkenny, Ireland; \\ L00130777@student.lyit.ie \\ 3 Department of Engineering, Letterkenny Institute of Technology, F92 FC93 Letterkenny, Ireland \\ * Correspondence: denismccrudden@lyit.ie; Tel.: +353-7491-8641
}

\section{check for}

updates

Citation: McCormick, W.; McDonagh, P.; Doran, J.; McCrudden,

D. Covalent Immobilisation of a Nanoporous Platinum Film onto a Gold Screen-Printed Electrode for Highly Stable and Selective Non-Enzymatic Glucose Sensing. Catalysts 2021, 11, 1161. https:// doi.org/10.3390/catal11101161

Academic Editors: Qiuchen Dong and Lei Jin

Received: 17 August 2021

Accepted: 24 September 2021

Published: 26 September 2021

Publisher's Note: MDPI stays neutra with regard to jurisdictional claims in published maps and institutional affiliations.

Copyright: (c) 2021 by the authors. Licensee MDPI, Basel, Switzerland. This article is an open access article distributed under the terms and conditions of the Creative Commons Attribution (CC BY) license (https:// creativecommons.org/licenses/by/ $4.0 /)$.

\begin{abstract}
Progress in the development of commercially available non-enzymatic glucose sensors continues to be problematic due to issues regarding selectivity, reproducibility and stability. Overcoming these issues is a research challenge of significant importance. This study reports a novel fabrication process using a double-layer self-assembly of (3 mercaptopropyl)trimethoxysilane (MPTS) on a gold substrate and co-deposition of a platinum-copper alloy. The subsequent electrochemical dealloying of the less noble copper resulted in a nanoporous platinum structure on the uppermost exposed thiol groups. Amperometric responses at $0.4 \mathrm{~V}$ vs. $\mathrm{Ag} / \mathrm{AgCl}$ found the modification to be highly selective towards glucose in the presence of known interferants. The sensor propagated a rapid response time $<5 \mathrm{~s}$ and exhibited a wide linear range from $1 \mathrm{mM}$ to $18 \mathrm{mM}$. Additionally, extremely robust stability was attributed to enhanced attachment due to the strong chemisorption between the gold substrate and the exposed thiol of MPTS. Incorporation of metallic nanomaterials using the self-assembly approach was demonstrated to provide a more reproducible and controlled molecular architecture for sensor fabrication. The successful application of the sensor in real blood serum samples displayed a strong correlation with clinically obtained glucose levels.
\end{abstract}

Keywords: nanoporous platinum film; MPTS; covalent immobilisation; glucose sensing; nonenzymatic; stability

\section{Introduction}

To date, enzymatic glucose sensors remain commercially unchallenged, mainly due to the high selectivity of the enzyme towards glucose. However, the inclusion of an enzyme in biosensor fabrication can cause the sensor to be affected by temperature, $\mathrm{pH}$, humidity and toxic chemicals [1]. Ensuring the stability of the immobilised enzyme and mediator on electrode surfaces also requires considerable attention, often involving elaborate fabrication processes [2].

To overcome the problems associated with an enzymatic biosensor, the fabrication of non-enzymatic glucose sensors has recently been intensively investigated to improve their electrocatalytic activity towards the oxidation of glucose. The non-enzymatic sensing of glucose based on the direct electrochemistry of glucose (oxidation or reduction) is a rapid and cost-effective approach [3]. As the sensor is enzyme-free, all associated enzymatic stability issues and enzyme immobilisation processes are removed from the fabrication process.

However, despite decades of research into non-enzymatic systems, problems associated with this approach have prevented its practical application. These include poor selectivity and reproducibility, slow kinetics of glucose, fouling of the electrode by real 
sample constituents and the limited number of modifications that are applicable to physiological $\mathrm{pH}$ [4]. Non-enzymatic electrocatalysts usually involve the use of a transition metal centre. Many different metals have been investigated, including nickel, copper, cobalt, gold, zinc and platinum [5-10]. Of these, platinum has been shown to be the most promising material, although its use as a smooth surface provides low sensitivity and poor selectivity and is susceptible to fouling of the surface [11].

More recent studies have reported that the successful fabrication of a non-enzymatic glucose sensor requires a high real surface area (with high roughness factor) [12]. This results in the highly sensitive and selective electro-oxidation of glucose. This is due to the fact that the adsorption of glucose on the electrode surface is a prerequisite step, and the electro-oxidation of common interfering electroactive species such as ascorbic acid, uric acid and $p$-acetamedophenol is independent of the electrode's roughness because it is diffusion-controlled [13].

Nanoparticles display attractive features in electrochemistry as a direct consequence of their nanodimensions. Their size and ultimately the electrochemical active area of the surface can be closely controlled using electrochemical deposition. Recently, nanoporous $\mathrm{Pt}$ has been reported to show high sensitivity and an excellent ability to be selective for glucose, while resisting interfering species. These advances were attributed to the increased roughness factor and porosity of the electrode surface, selectively enhancing the current of a sluggish reaction. This feature also resulted in an excellent antifouling property [14,15].

Many reports exist where nanomaterials are prepared, characterised and then applied in microliter quantities to the electrode surface. Such modifications have advanced the non-enzymatic detection of glucose [15-20]. However, modifying an electrode in this way can lead to issues with regard to stability and reproducibility. Self-assembled monolayers (SAMs), in contrast, have the ability to provide a more reproducible, simple and reliable procedure to immobilise molecules on various metal surfaces [21-23]. SAM formation is an easy method recently used for selected metal nanoparticle chemisorption onto surfaces such as gold, platinum or silver [6]. In chemisorption, much stronger and more stable covalent bonds are formed between the adsorbate and the electrode surface.

In an effort to produce a reliable, reproducible non-enzymatic sensor for glucose, this study describes the immobilisation of a two-stage self-assembled monolayer of (3mercaptopropyl)trimethoxysilane (MPTS) onto a gold surface. A nanoporous platinum surface is then covalently attached to exposed thiol groups of the MPTS from copper platinum solutions using a voltammetric alloying/dealloying procedure. The surface area of the resulting nanoporous platinum surface is controlled by the number of voltammetric cycles. The sensor is then investigated with regard to its ability to accurately detect glucose in the presence of common interferents and with regard to stability and reproducibility.

\section{Results and Discussion}

\subsection{Electrode Preparation}

During the fabrication of the modified sensor, it was imperative that the gold surface was as clean as possible to promote the interaction of gold with the thiol-terminated molecules of the MPTS. Therefore, an electrochemical cleaning step was performed by subjecting the gold electrode to cyclic voltammetry $(\mathrm{CV})$ in a $0.5 \mathrm{M}$ sulphuric acid solution. The voltammetric response of the gold electrode in $0.5 \mathrm{M}$ sulphuric acid displays typical characteristic peaks, shown in Figure 1. The peaks in the anodic scan correspond to different forms of oxide species on the gold surface, and the single reduction peak in the cathodic scan is due to the removal of the oxide layer when reversing the scan direction. The scan obtained was typical of a clean gold electrode in an acidic solution. 


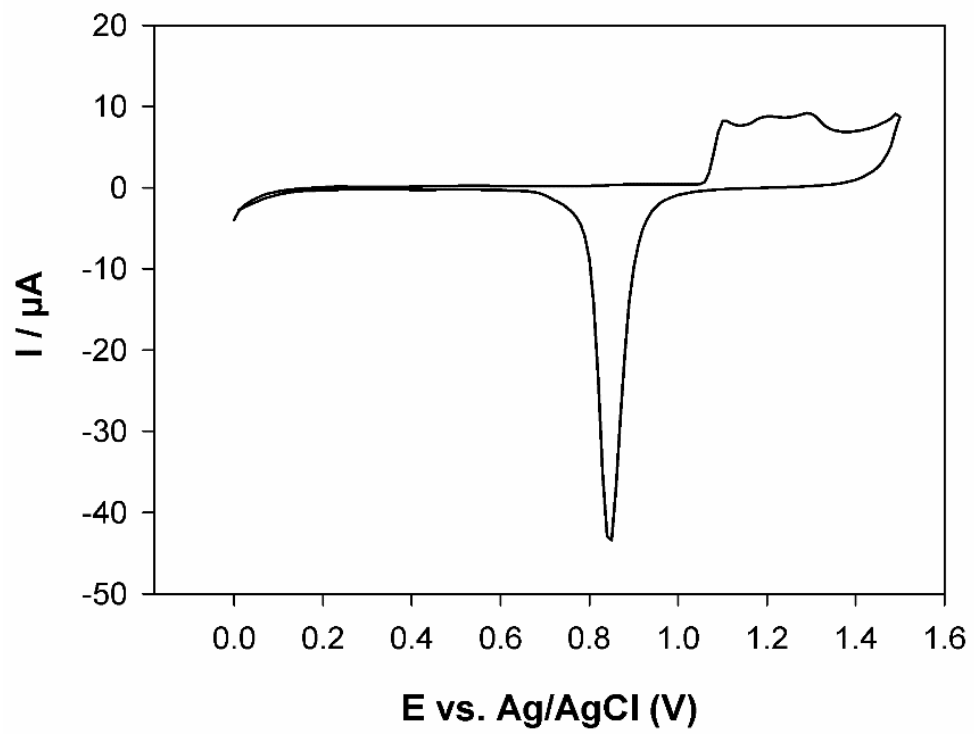

Figure 1. Cyclic voltammogram of the gold electrode in $0.1 \mathrm{M} \mathrm{H}_{2} \mathrm{SO}_{4}$ between 0.0 and $1.5 \mathrm{~V}$ vs. $\mathrm{Ag} / \mathrm{AgCl}$ in $0.5 \mathrm{M} \mathrm{H}_{2} \mathrm{SO}_{4}$ at a scan rate of $0.1 \mathrm{~V} \mathrm{~s}^{-1}$.

\subsection{Au-MPTS-Pt Fabrication}

The fabrication of the sensor involved immersing the prepared gold electrode in the MPTS solution. MPTS was chosen in this self-assembly approach as, structurally, it possesses two reactive functional groups-the thiol tail and the methoxy headgroup. The thiol tail allows covalent attachment to the gold surface, while the methoxy group can undergo hydrolysis and condensation reactions [24]. This immersion resulted in the attachment of a self-assembled monolayer of MPTS onto the surface by the formation of $\mathrm{Au}-\mathrm{S}$ bonds. The electrode was then immersed in $0.01 \mathrm{M} \mathrm{NaOH}$, causing the hydrolysis of the self-assembled monolayer through a polycondensation reaction, forming exposed silane units arranged in a 2-dimensional (2D) network. A second immersion of the electrode into the MPTS solution resulted in the formation of a second silane layer via Si-O-Si bonds, producing a surface containing many exposed thiol moieties. The fabrication process of the sensor is shown in Scheme 1. Chemisorption of a nanoporous platinum surface onto the MPTS 2D network was performed by the electrochemical co-deposition of a platinumcopper alloy and the subsequent electrochemical dealloying of the less noble copper using a previously described method [25]. A platinum-copper layer was deposited during the cathodic scan, while removal of the less noble alloying partner in the return scan yielded a porous platinum structure.

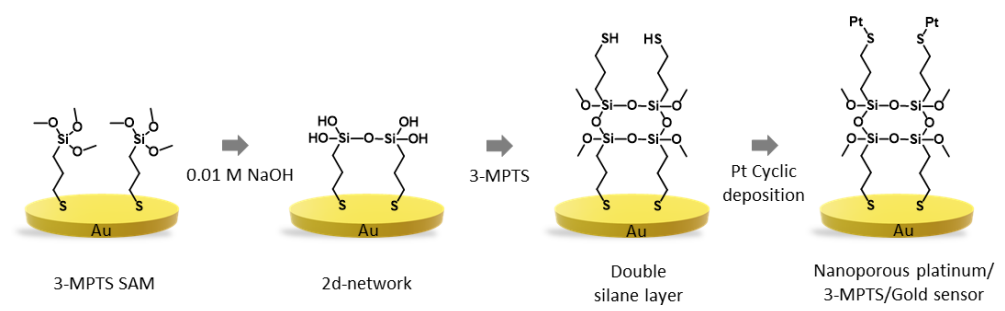

Scheme 1. Schematic diagram showing steps involved in the fabrication of the Au-MPTS-Pt.

\subsection{Characterisation of $A u-M P T S-P t$}

The increase in the surface area of Pt chemisorbed on the MPTS/Au electrode was monitored by electrochemical cycling between -0.25 and $1.4 \mathrm{~V}$ in $0.5 \mathrm{M} \mathrm{H}_{2} \mathrm{SO}_{4}$. Voltammograms displayed a platinum oxide reduction peak at $0.42 \mathrm{~V}$ vs. $\mathrm{Ag} / \mathrm{AgCl}$ reference electrode similar to that reported previously [26] (Figure 2). 


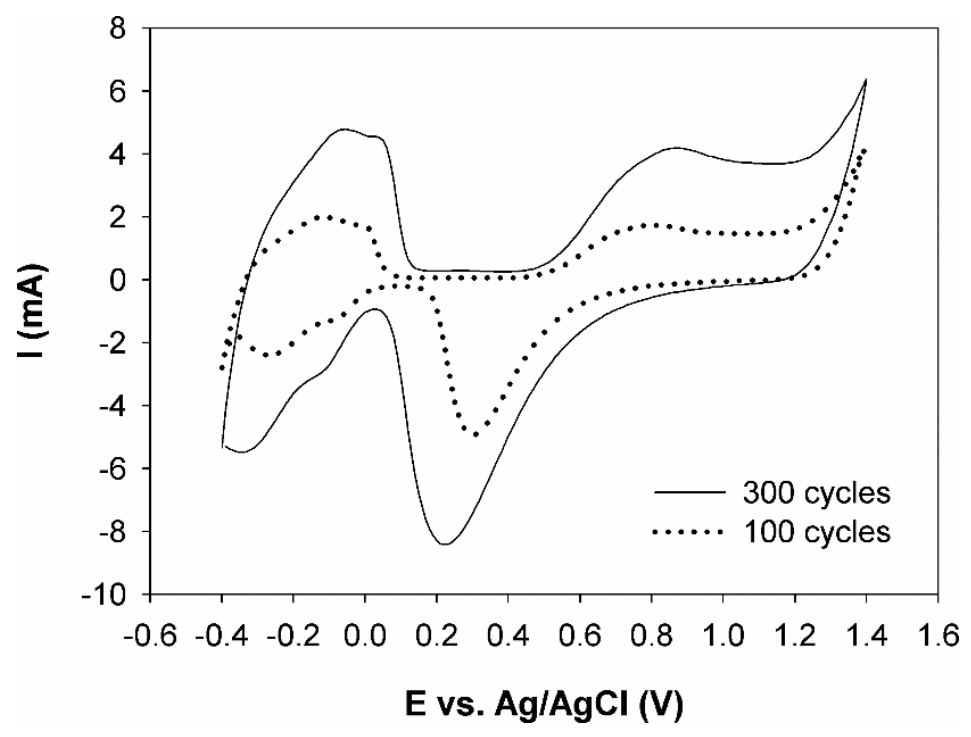

Figure 2. Cyclic voltammograms of the Au-MPTS-Pt after 100 and 300 platinum deposition cycles. CVs were performed in $0.5 \mathrm{M} \mathrm{H}_{2} \mathrm{SO}_{4}$ at a scan rate of $50 \mathrm{mV} \mathrm{s}^{-1}$.

In this study, the oxygen absorption method was used to determine the real surface area of the platinum-modified electrodes. The area under the platinum oxide peak in the CV scan was determined using the automatic peak search option on the potentiostat. The real surface area $\left(\mathrm{cm}^{2}\right)$ of the modified electrode was determined by dividing the area un-der the oxide reduction peak $(\mu \mathrm{C})$ by a correction factor of $420 \mu \mathrm{C} \mathrm{cm}{ }^{-2}$ for a platinum electrode [27]. The surface roughness factor $(r f)$ was then calculated by dividing the real surface area $\left(\mathrm{cm}^{2}\right)$ by the geometric area $\left(\mathrm{cm}^{2}\right)$. The electrode subjected to 100 cycles produced a $r f$ of 235 , while the electrode cycled 300 times created a $r f$ of 612 .

These $r f$ values indicate a significant increase in the electrochemical surface area of immobilised platinum nanoparticles after 300 cycles when compared to that recorded after 100 cycles. Each cycle increased the surface area of the formed nanoporous platinum, resulting in an increased area being available for gold oxide formation in the forward scan and consequently an increase in the reduction peak area in the return scan. Recent studies have demonstrated that nanoporous platinum surfaces deliver many advantages, including a stable, self-supporting, nanometre-sized structure coupled with increased catalytic activity and selectivity for glucose due to the high surface area of the porous surface $[15,25,26,28]$.

Scanning electron microscopy analysis was performed to determine the surface morphology characteristics of the electrode. Figure 3 depicts the FE-SEM images of the surface of the electrode before modification (A) and at different magnifications of the modification (B, C and D). The SEM image of the unmodified gold substrate displays a flat morphology with some ridges and pits (Figure 3A). The SEM image of the nanoporous platinum modified electrode (Figure 3B) shows well-dispersed, spherical platinum clusters with an approximate size of $2 \mu \mathrm{m}$. Detailed images at higher magnification of the modified electrode are shown in Figure 3C,D. The platinum clusters contained nanopores of approximately 10 to $20 \mathrm{~nm}$ in size, which can be clearly observed in Figure 3D. 

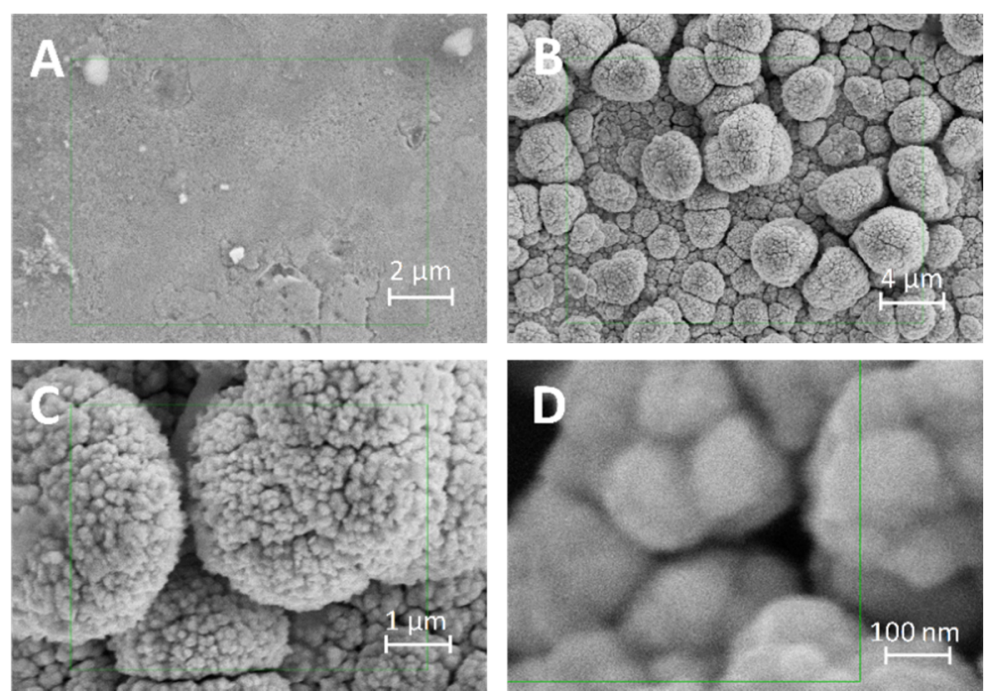

Figure 3. SEM images of the morphology of the electrode surface before (A) and after 300 cycles (B-D): gold surface prior to modification (A), nanoporous platinum surface at $\times 5 \mathrm{k}(\mathbf{B}), \times 20 \mathrm{k}(\mathbf{C})$ and $\times 60.1 \mathrm{k}$ magnification $(\mathrm{D})$.

The chemical composition of the nanoporous platinum layer was determined by energy-dispersive X-ray spectroscopy (EDX) (Figure 4). Figure 4A shows the spectrum obtained from the electrode that was subjected to 100 deposition cycles, while Figure 4B shows the results from the electrode that had undergone 300 deposition cycles. Both EDX spectra of the nanoporous platinum layer confirm the presence of platinum as the element of the highest percentage weight. Increased deposition cycles in Figure $4 \mathrm{~B}$ produced an increase in Pt signal (45.0 to 71.9\%), which, consequently, led to a reduction in the Si signal (4.9 to $0.8 \%$ ) from the MPTS. This confirms that with increasing deposition cycles, the platinum percentage weight increased and the available MPTS attachment sites decreased as they were continuously being occupied by platinum. The Au signal was due to the gold substrate on which the platinum was deposited. Other elements appearing in the EDX spectrum were $\mathrm{Cu}$, coming from the residual copper after the dealloying process, and $\mathrm{O}$ and C, which were present due to the use of MPTS as the organic linker in the fabrication of the electrode.

The nanoporous Pt surface was analysed by XPS. Figure 5B shows the high-resolution spectra for $\mathrm{Pt} 4 \mathrm{f}$. The doublet structure revealed dual components with assigned binding energies at $76.7 \mathrm{eV}, 4 \mathrm{f}_{7 / 2}$ and $79.9 \mathrm{eV}, 4 \mathrm{f}_{5 / 2}$. These increased energies can be associated with charging on the platinum surface and increased final state effects due to the nanoparticle size [29]. Previous studies have also shown that Pt-S bond formation can cause a shift in $\mathrm{Pt}$ 4f spectra [30]. This would correspond with the covalent nature of the interaction between platinum and the silane linker. 

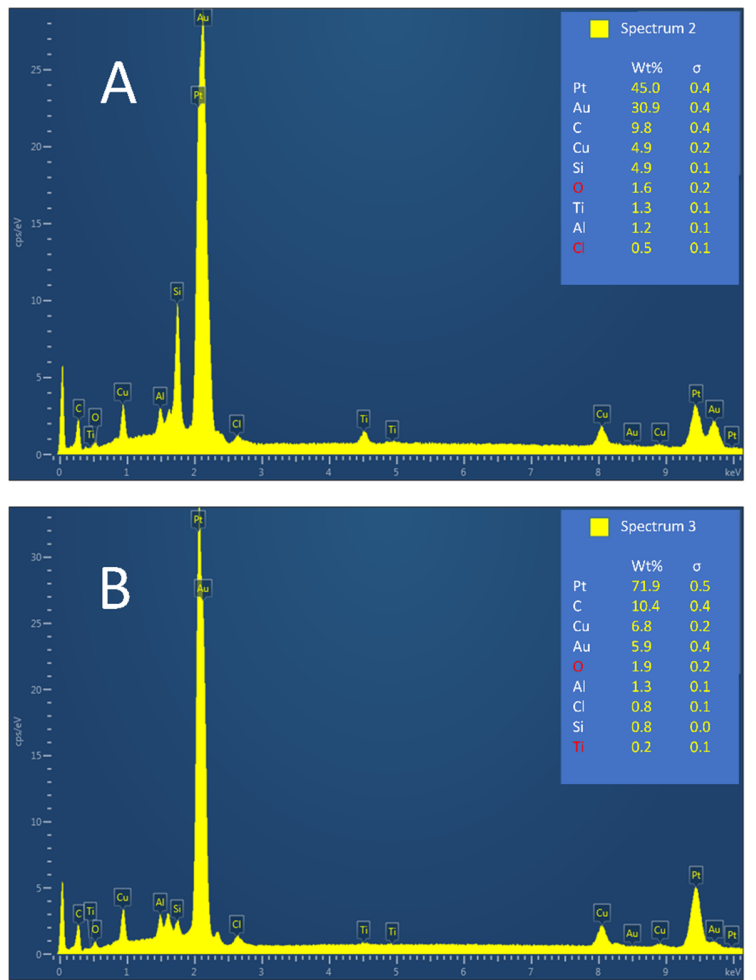

Figure 4. EDX spectra of the modified electrode surface. Electrode composition after 100 cycles (A). Electrode composition after 300 cycles (B).
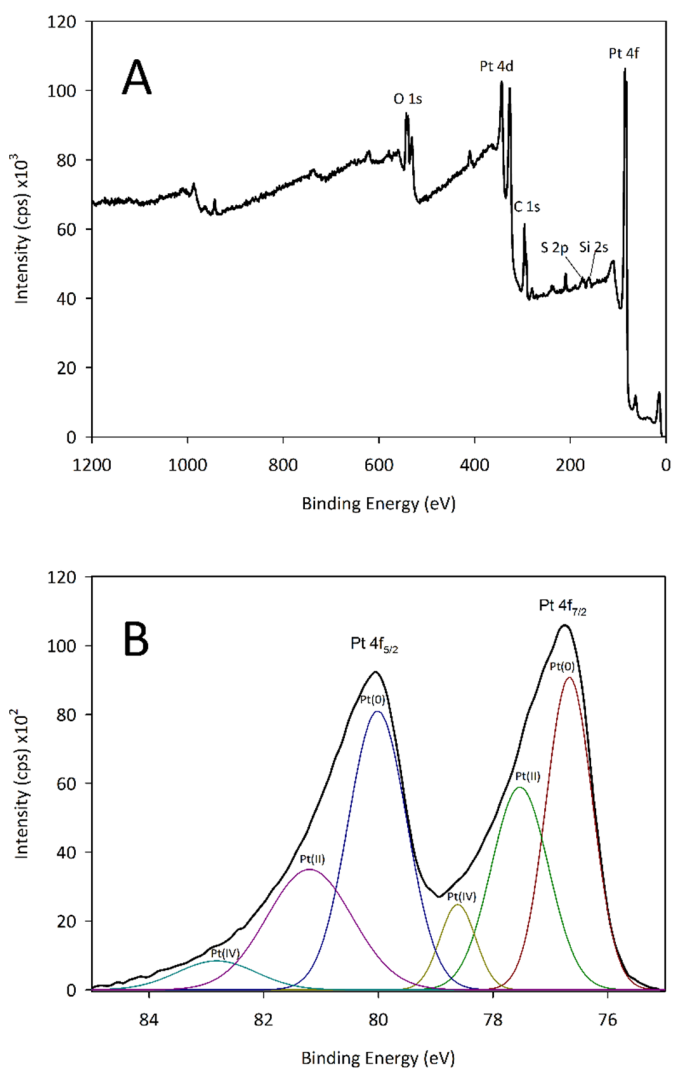

Figure 5. XPS spectra of the electrode surface after 300 cycles. Survey scan (A); high-resolution scan for platinum $4 \mathrm{f}(\mathbf{B})$. 


\subsection{Electrochemical Detection of Glucose}

Cyclic voltammetry was used to evaluate the response of the sensor towards glucose oxidation (voltammograms not shown). The potential at which glucose was oxidised was determined from the addition of glucose concentrations $(2,4$ and $6 \mathrm{mM})$ into $0.1 \mathrm{M}$ PBS. A glucose oxidation peak occurred between 0.35 and $0.45 \mathrm{~V}$, which agrees with previous studies by this group when using a platinum surface [14]. The area of the peak increased linearly with glucose concentration. The performance of the modified platinum electrode was compared with different glucose sensors, as shown in Table 1.

Table 1. Comparison of the performance of different platinum-based glucose sensors.

\begin{tabular}{|c|c|c|c|c|c|}
\hline $\begin{array}{c}\text { Electrode } \\
\text { Modification }\end{array}$ & Potential (V) & Linear Range (mM) & $\begin{array}{c}\text { Sensitivity ( } \mu \mathrm{A} \\
\mathbf{m M}^{-1} \mathbf{c m}^{-2} \text { ) }\end{array}$ & $\begin{array}{l}\text { Detection Limit } \\
(\mu \mathrm{M})\end{array}$ & Year and Ref. \\
\hline PtNPs/CNCs & $-0.30^{[a]}$ & $0.05-10.0$ & - & 20 & 2017 [31] \\
\hline $\begin{array}{l}\text { Hierarchical Pt micro- } \\
\text { /nanostructures }\end{array}$ & $+0.45^{\text {[a] }}$ & Up to 3.0 & 473 & 85 & 2018 [32] \\
\hline $\mathrm{PtAu} / \mathrm{C}$ & $-0.33^{[b]}$ & $0.01-10$ & - & 3 & 2020 [33] \\
\hline $\mathrm{ZnO}-\mathrm{Pt}-\mathrm{g}-\mathrm{C}_{3} \mathrm{~N}_{4}$ & $+0.20^{[a]}$ & $0.25-110$ & 3.34 & 0.1 & $2020[34]$ \\
\hline $\mathrm{Pt}-\mathrm{CuO} / \mathrm{GPE}$ & $+0.60[\mathrm{a}]$ & Up to 25 & 2035 & 0.1 & 2020 [35] \\
\hline PtNi alloy-graphene & $+0.30^{[\mathrm{a}]}$ & $0.5-15.0$ & 24.03 & 16 & $2020[36]$ \\
\hline $\begin{array}{c}\text { Pt-Au- } \\
\text { graphene/GCE }\end{array}$ & $-0.10^{[\mathrm{b}]}$ & $1.0-25.0$ & 26.33 & 4.0 & 2014 [37] \\
\hline $\mathrm{Pt}-\mathrm{CuO} / \mathrm{rGO}$ & $+0.60^{[a]}$ & $0.0005-12$ & 3577 & 0.01 & 2014 [38] \\
\hline Pt nanoporous & $+0.40^{[\mathrm{a}]}$ & $1.0-10.0$ & 5.67 & 800 & 2017 [26] \\
\hline Au-MPTS-Pt & $+0.40^{\text {[a] }}$ & $\begin{array}{c}1.0-7.0 \\
7.0-18.0\end{array}$ & $\begin{array}{l}191.67 \\
135.98\end{array}$ & 37 & This work \\
\hline
\end{tabular}

${ }^{[\mathrm{a}]}$ vs. Ag/ $\mathrm{AgCl} .{ }^{[\mathrm{b}]}$ vs. SCE.

\subsection{Interference Study}

A major challenge associated with non-enzymatic glucose sensors is eliminating the effects of other physiological interferences commonly found in blood. These interferents can often be oxidised at the same working potential as glucose, which can result in an overestimation of the analyte. The selectivity of Au-MPTS-Pt was investigated by measuring the amperometric response of glucose at potentials of $0.35,0.40$ and $0.45 \mathrm{~V}$ in the presence of the common interferents (Figure 6). In physiological conditions, interfering compounds exist at lower concentrations when compared to glucose levels.

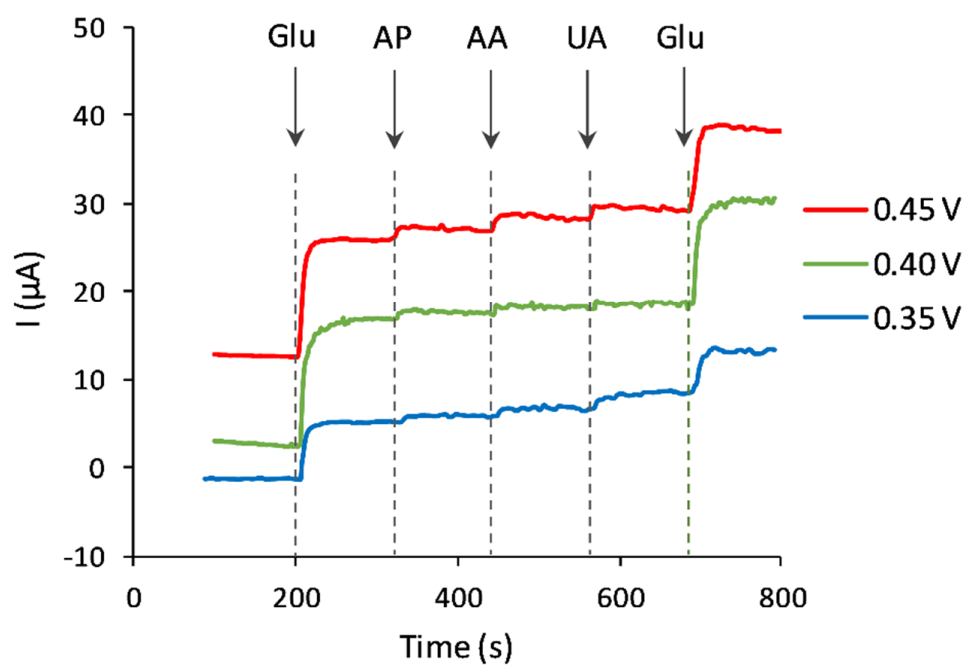

Figure 6. Amperometric responses of the Au-MPTS-Pt to successive additions of $1 \mathrm{mM}$ glucose, $0.1 \mathrm{mM}$ AP, $0.1 \mathrm{mM}$ AA, $0.1 \mathrm{mM}$ UA and $1 \mathrm{mM}$ glucose, respectively, in $0.1 \mathrm{M} \mathrm{PBS}$ (pH 7.4) at applied potentials of $0.35 \mathrm{~V}$ (blue), $0.40 \mathrm{~V}$ (green) and $0.45 \mathrm{~V}$ (red). 
Therefore, the amperometric response of the Au-MPTS-Pt to successive additions of 1 $\mathrm{mM}$ glucose, $0.1 \mathrm{mM}$-acetamidophenol (AP), $0.1 \mathrm{mM}$ ascorbic acid (AA), $0.1 \mathrm{mM}$ uric acid (UA) and $1 \mathrm{mM}$ glucose (Glu), respectively, in a stirred $0.1 \mathrm{M}$ phosphate buffer ( $\mathrm{pH} 7.4$ ) was investigated. Figure 5 shows the change that occurs in the amperometric response at different potentials. There is a minimal response to interfering species at $0.4 \mathrm{~V}$, with no significant effect on the recovery of glucose, which suggests the anti-interference capability and high selectivity of the Au-MPTS-Pt electrode at this potential.

\subsection{Amperometric Measurement of Glucose}

The performance of the nanoporous Au-MPTS-Pt towards the detection of glucose was then studied by recording the amperometric response at $0.4 \mathrm{~V}$ in stirred phosphate buffer (Figure 7). Upon successive additions of $1 \mathrm{mM}$ glucose at regular intervals, significant and fast current responses were observed using the modified electrode, with a steady-state current being achieved within $5 \mathrm{~s}$.

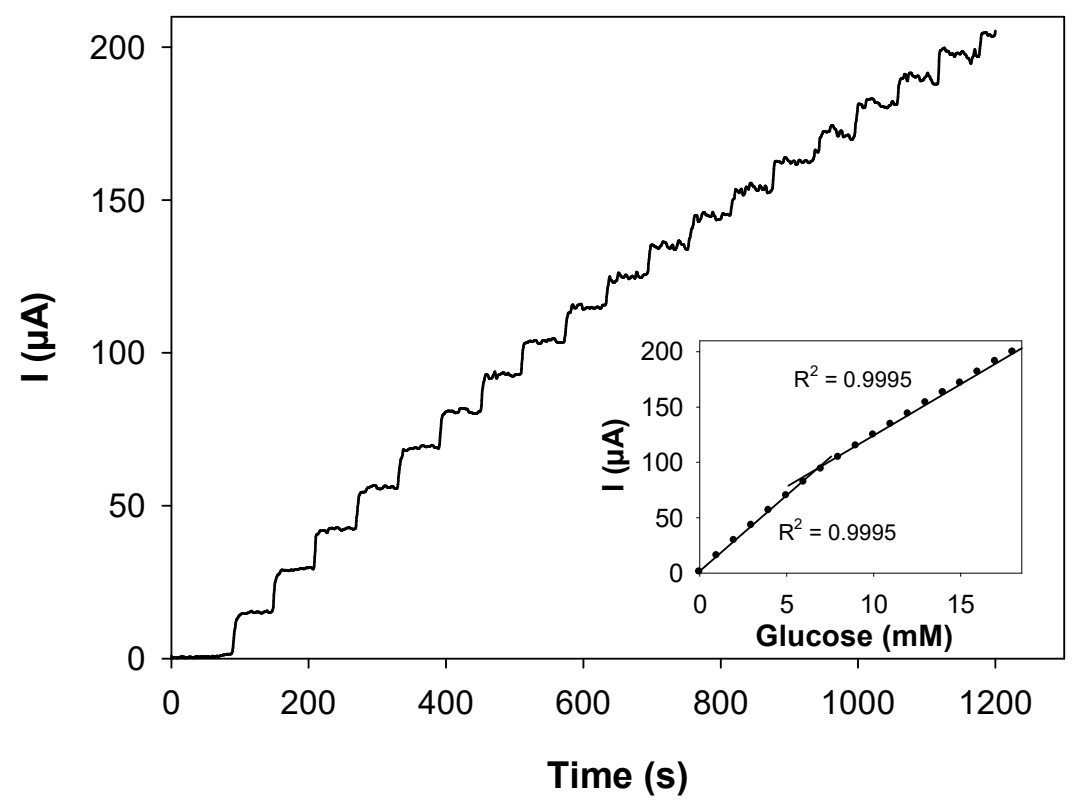

Figure 7. Amperometric response of the Au-MPTS-Pt towards successive additions of $1 \mathrm{mM}$ glucose into a stirring solution of $0.1 \mathrm{M}$ phosphate buffer $(\mathrm{pH} 7.4)$ at a constant potential of $0.4 \mathrm{~V}$. Inset: Calibration curve of the Au-MPTS-Pt amperometric response of the glucose concentrations against the corresponding current generated. Sensitivity: 1 to $7 \mathrm{mM}$ and 7 to $18 \mathrm{mM}$ are 191.67 and $135.98 \mu \mathrm{A}$ $\mathrm{mM}^{-1} \mathrm{~cm}^{-2}$, respectively.

The calibration curve (inset) displays two distinct regions of linearity, similar to the response reported in a number of previous studies [39-43]. The first region provided a linear range from 1 to $7 \mathrm{mM}$ glucose with a regression coefficient of 0.9995 and a sensitivity value of $191.67 \mu \mathrm{A} \mathrm{mM} \mathrm{m}^{-1} \mathrm{~cm}^{-2}$. The second region displayed a linear range from 7 to 18 $\mathrm{mM}$ glucose with a regression coefficient of 0.9995 and sensitivity of $135.98 \mu \mathrm{A} \mathrm{mM}-1 \mathrm{~cm}^{-2}$.

\subsection{Analysis of Real Samples}

Validation studies for the practical application of the Au-MPTS-Pt sensor in real blood serum samples were performed. The sensor was employed to determine the glucose concentration in three clinically validated serum samples obtained from the local university hospital. The samples did not undergo further pre-treatment before the analysis. For each sample, the current response at $0.4 \mathrm{~V}$ was recorded for $0.5 \mathrm{~mL}$ of serum added to $9.5 \mathrm{~mL}$ of 0.1 M PBS (pH 7.4). The glucose content of the serum samples was then calculated from the calibration plot. Results shown in Table 2 display a high degree of accuracy relative to the clinically validated samples. 
Table 2. Determination of glucose in human blood serum samples.

\begin{tabular}{cccc}
\hline \multirow{2}{*}{ Sample } & $\begin{array}{c}\text { Hospital Laboratory } \\
(\mathbf{m M})\end{array}$ & Au/MPTS/Pt (mM) & Recovery (\%) \\
\hline 1 & 5.08 & 5.09 & 100.2 \\
2 & 7.16 & 7.11 & 99.3 \\
3 & 3.75 & 3.55 & 94.7 \\
\hline
\end{tabular}

\subsection{Reusability, Stability and Reproducibility}

The reusability of a single sensor was evaluated by measuring the amperometric response to 10 samples each containing $1 \mathrm{mM}$ glucose in $0.1 \mathrm{M}$ PBS (Figure 8A). The investigation showed that the sensor exhibits high reusability, with $97 \%$ of the sensor's initial response being recorded after ten uses.

(A)

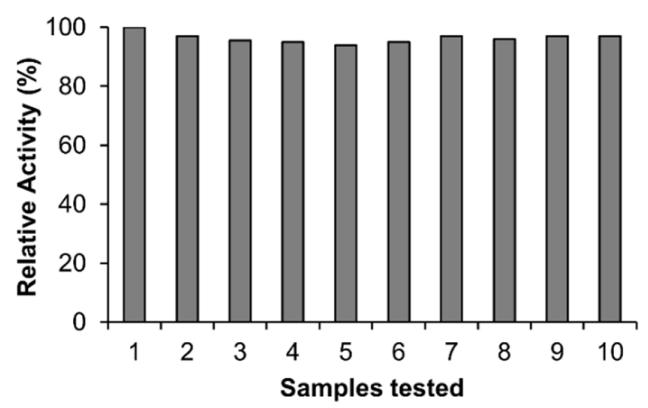

(B)

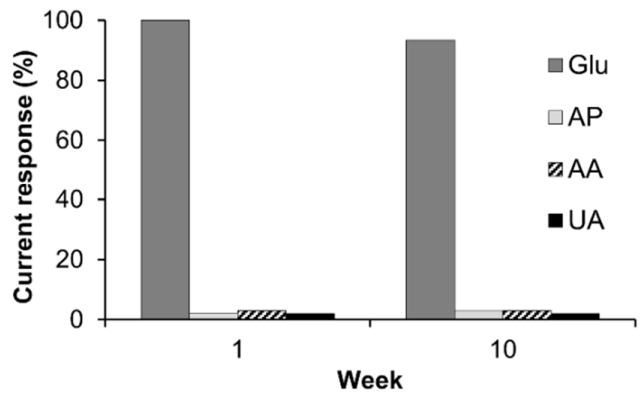

(C)

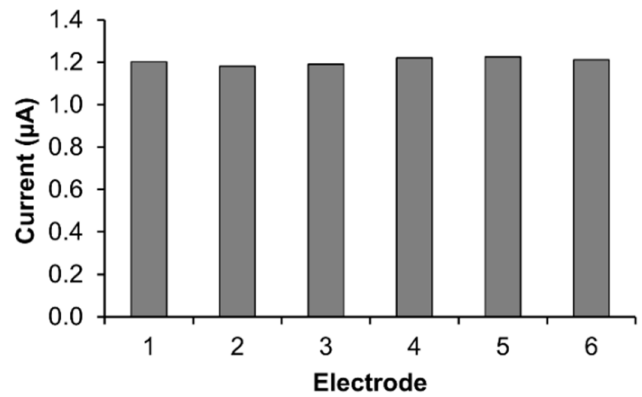

Figure 8. Reusability: Amperometric responses of a Au-MPTS-Pt sensor to ten $1 \mathrm{mM}$ glucose samples in $0.1 \mathrm{M}$ PBS at the applied potential of $0.4 \mathrm{~V}$ (A). Stability: Amperometric responses of the AuMPTS-Pt to additions of $1 \mathrm{mM}$ glucose and $0.1 \mathrm{M}$ interferences in $0.1 \mathrm{M}$ PBS at week 1 and week 10 (B). Reproducibility: Amperometric responses of six independently fabricated Au-MPTS-Pt sensors to additions of $1 \mathrm{mM}$ glucose in $0.1 \mathrm{M}$ PBS (C).

The stability of a sensor stored at room temperature was evaluated by measuring the amperometric response to $1 \mathrm{mM}$ glucose and $0.1 \mathrm{mM}$ interferants every week for ten weeks. 
The results in Figure 8B show the sensor's response to glucose and interferents during week 1 and week 10 . The responses are displayed as a percentage of the sensor's initial value, with $93.4 \%$ of the sensor's initial response being recorded after ten weeks.

The reproducibility was evaluated by measuring the amperometric response to $1 \mathrm{mM}$ glucose in $0.1 \mathrm{M}$ PBS using six independently fabricated sensors. The current response of each sensor is presented in Figure $8 \mathrm{C}$ and shows a relative standard deviation (RSD) of $1.45 \%$.

\section{Materials and Methods}

\subsection{Materials}

All reagents were of analytical grade and used as purchased without further purification. Hexachloroplatinic acid hydrate $\left(\mathrm{H}_{2} \mathrm{PtCl}_{6}\right)$, copper (II) sulphate $\left(\mathrm{CuSO}_{4}\right)$, methanol

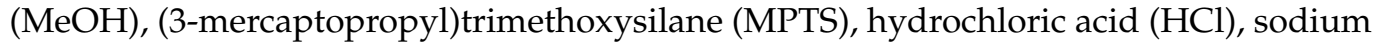
hydroxide $(\mathrm{NaOH})$, potassium phosphate monobasic $\left(\mathrm{KH}_{2} \mathrm{PO}_{4}\right)$, potassium phosphate dibasic $\left(\mathrm{K}_{2} \mathrm{HPO}_{4}\right)$, L-ascorbic acid (AA), uric acid (UA), acetamidophenol (AP) and glucose were obtained from Sigma Aldrich (Ireland). Sulphuric acid $\left(\mathrm{H}_{2} \mathrm{SO}_{4}\right)$ and D-glucose were purchased from Fisher Scientific (Loughborough, UK). Ultra-purified water (resistivity $\leq 18 \mathrm{M} \Omega \mathrm{cm}$ ) supplied by a Milli-Q system (Millipore, Darmstadt, Germany) was used in the preparation of all solutions.

All electrochemical measurements were performed using a CHI660 potentiostat (Shanghai CH Instrument Company, Shanghai, China) and a personal computer for data storage and processing. The electrode assembly consisted of a screen-printed gold working electrode $(3 \mathrm{~mm} \varnothing)$, a silver/silver chloride reference $(3 \mathrm{M} \mathrm{KCl})$ and a platinum counter electrode.

\subsection{Fabrication of the Modified Electrode}

The disposable gold electrode was electrochemically cleaned by cycling 50 times be-tween -0.2 and $1.5 \mathrm{~V}$ vs. $\mathrm{Ag} / \mathrm{AgCl}$ in $0.5 \mathrm{H}_{2} \mathrm{SO}_{4}$ at a scan rate of $0.1 \mathrm{~V} \mathrm{~s}^{-1}$ until a reproducible scan typical for a gold surface was achieved. The MPTS solution was prepared by placing $100 \mu \mathrm{L}$ MPTS, $300 \mu \mathrm{L} \mathrm{MeOH}, 300 \mu \mathrm{L}$ ultrapure water and $100 \mu \mathrm{L}$ hydrochloric acid in a conical flask. The solution was then sonicated in a sonic bath for 30 min to allow gelation to occur.

Spontaneously assembled monolayers were formed by immersing the gold electrode in the MPTS solution for $3 \mathrm{~h}$. The electrode was thoroughly rinsed with ultrapure water and immersed in aqueous $0.01 \mathrm{M} \mathrm{NaOH}$ for $2 \mathrm{~h}$, causing the silane units of the MPTS to become polymerised into a 2D network. A second silane layer was formed by immersing the electrode back in the MPTS solution for $12 \mathrm{~h}$. The MPTS-modified electrode was rinsed several times with ultrapure water.

A $20 \mathrm{mM} \mathrm{H}_{2} \mathrm{PtCl}_{6}$ and $20 \mathrm{mM} \mathrm{CuSO}_{4}$ solution was made by adding $0.0414 \mathrm{~g}_{\text {of }} \mathrm{H}_{2} \mathrm{PtCl}_{6}$ and $0.025 \mathrm{~g}$ of $\mathrm{CuSO}_{4}$ to a $5 \mathrm{~mL}$ volumetric flask and adding $0.5 \mathrm{M} \mathrm{H}_{2} \mathrm{SO}_{4}$. Platinum nanoparticles were electrodeposited onto the MPTS layer by cyclic voltammetry according to a procedure by Kloke and co-workers [28]. The attachment of platinum nanoparticles to the MPTS layer was achieved by multiple repetitions of the electrochemical co-deposition of a platinum-copper alloy and subsequent electrochemical dealloying of copper. This procedure involved subjecting the working electrode to up to $300 \mathrm{CV}$ scans in the platinumcopper solution. The potential range was from 1.4 to $-0.6 \mathrm{~V} v \mathrm{vs}$. $\mathrm{Ag} / \mathrm{AgCl}$ at a scan rate of $50 \mathrm{mV} \mathrm{s}^{-1}$. The electrode was rinsed with ultrapure water, dried with nitrogen and stored at room temperature. The modified electrode was denoted as Au-MPTS-Pt.

\subsection{Structural and Morphological Analysis}

The morphological and structural observations were obtained by scanning electron microscopy (SEM) using a Hitachi Regulus 8230. The elemental composition was confirmed by energy-dispersive $x$-ray spectroscopy (EDX) analysis using an Oxford Instruments Ultim Max 170 and X-ray photoelectron spectroscopy (XPS) using a Kratos Axis Ultra DLD. 


\subsection{Electrochemical Surface Roughness Determination}

Electrochemical characterisation of the Au-MPTS-Pt was performed using cyclic voltammetry by subjecting the electrode to 10 scans in $0.5 \mathrm{M} \mathrm{H}_{2} \mathrm{SO}_{4}$ in the potential range from -0.25 to $1.4 \mathrm{~V}$ vs. $\mathrm{Ag} / \mathrm{AgCl}$ at a scan rate of $0.05 \mathrm{~V} \mathrm{~s}^{-1}$. The charge $(\mu \mathrm{C})$ associated with the area under the platinum oxide reduction peak in the final scan was divided by a con-version factor of $420 \mu \mathrm{C} \mathrm{cm}^{-2}$, giving the real electrochemical area of the electrode $\left(\mathrm{cm}^{2}\right)$. The real electrochemical area was divided by the geometric area $\left(\mathrm{cm}^{2}\right)$ to produce a sur-face roughness factor.

\subsection{Cyclic Voltammetric Detection of Glucose}

The electrocatalytic activity of the sensor towards glucose oxidation was investigated by cyclic voltammetry. The applied potential ranged from -0.6 to $0.8 \mathrm{~V}$ at a scan rate of $100 \mathrm{mV} \mathrm{s}^{-1}$. A blank scan and varying glucose concentrations $(2,4$ and $6 \mathrm{mM})$ were recorded by cycling the electrode in $20 \mathrm{~mL}$ of $0.1 \mathrm{M}$ PBS.

\subsection{Amperometric Detection of Glucose and Interferences}

For amperometric detection, the electrode was immersed in a rapidly stirred solution of $0.1 \mathrm{M}$ PBS $(20 \mathrm{~mL})$ to provide convective transport and the potential was held at different values from 0.35 to $0.45 \mathrm{~V}$. The linear range was determined by additions of $1 \mathrm{mM}$ glucose at regular intervals. The selectivity of the electrode was determined by an initial addition of $1 \mathrm{mM}$ glucose followed by additions of $0.1 \mathrm{mM}$ interfering species and a final addition of $1 \mathrm{mM}$ glucose. Additions were delivered in increments of $100 \mathrm{~s}$.

Glucose concentrations in serum samples obtained from a local hospital laboratory were determined using the modified electrode by the addition of $0.5 \mathrm{~mL}$ of serum to $9.5 \mathrm{~mL}$ of $0.1 \mathrm{M}$ PBS. Values found were compared to those recorded in the medical laboratory.

\section{Conclusions}

Non-enzymatic glucose sensors were successfully fabricated using nanoporous platinum attached to gold screen-printed substrates using a MPTS 2D monolayer. The platinum nanoporous layer was electrochemically deposited by cyclic voltammetry. The modified electrode exhibited good stability and selectivity towards glucose in the presence of interfering compounds commonly found in human blood serum. The sensor also dis-played a wide linear range, fast response time, good reproducibility and excellent reusability. The sensor also provided accurate glucose measurements in human blood serum samples obtained from the local hospital. Nanoporous platinum provided a highly selective glucose sensing platform, while the MPTS self-assembly approach of modification resulted in increased stability and reproducibility. The above attributes of the fabricated sensor may provide a new approach to practical glucose determination in real samples.

Author Contributions: Conceptualization, W.M. and D.M.; methodology, W.M., P.M. and D.M.; validation, W.M., P.M. and D.M.; investigation, W.M. and P.M.; writing—original draft preparation, W.M., P.M. and D.M.; writing-review and editing, W.M., P.M. and D.M.; visualization, W.M.; supervision, D.M., J.D.; project administration, D.M., J.D. All authors have read and agreed to the published version of the manuscript.

Funding: This research received no external funding.

Acknowledgments: The authors acknowledge support from Martin Warren and his technical team, University of Kent, UK, for providing surface characterisation analysis.

Conflicts of Interest: The authors declare no conflict of interest.

\section{References}

1. Schijgerl, K.; Hitzmann, B.; Jurgens, H.; Kullick, T.; Ulber, R.; Weigal, B. Challenges in Integrating Biosensors and FIA for On-Line Monitoring and Control. Trends Biotechnol. 1996, 14, 21-23. [CrossRef]

2. Mehrotra, P. Biosensors and their applications-A review. J. Oral Biol. Craniofacial Res. 2016, 6, 153-159. Available online: https:/ / pubmed.ncbi.nlm.nih.gov/27195214 (accessed on 23 April 2021). [CrossRef] 
3. Wang, G.; He, X.; Wang, L.; Gu, A.; Huang, Y.; Fang, B.; Geng, B.; Zhang, X. Non-enzymatic electrochemical sensing of glucose. Microchim. Acta 2013, 180, 161-186. [CrossRef]

4. Park, S.; Boo, H.; Chung, T.D. Electrochemical non-enzymatic glucose sensors. Anal Chim. Acta. 2006, 556, 46-57. [CrossRef] [PubMed]

5. Liu, Z.; Guo, Y.; Dong, C. A high performance nonenzymatic electrochemical glucose sensor based on polyvinylpyrrolidonegraphene nanosheets-nickel nanoparticles-chitosan nanocomposite. Talanta 2015, 137, 87-93. Available online: http://www. sciencedirect.com/science/article/pii/S003991401500065X (accessed on 14 May 2021). [CrossRef]

6. Zhao, J.; Wang, F.; Yu, J.; Hu, S. Electro-oxidation of glucose at self-assembled monolayers incorporated by copper particles. Talanta 2006, 70, 449-454. Available online: http:/ / www.sciencedirect.com/science/article/pii/S0039914006002013 (accessed on 16 May 2021). [CrossRef] [PubMed]

7. Hui, N.; Wang, J. Electrodeposited honeycomb-like cobalt nanostructures on graphene oxide doped polypyrrole nanocomposite for high performance enzymeless glucose sensing. J. Electroanal. Chem. 2017, 798, 9-16. Available online: http://www. sciencedirect.com/science/article/pii/S1572665717303740 (accessed on 30 May 2021). [CrossRef]

8. Jeong, H.; Nguyen, D.M.; Lee, M.S.; Kim, H.G.; Ko, S.C.; Kwac, L.K. N-doped graphene-carbon nanotube hybrid networks attaching with gold nanoparticles for glucose non-enzymatic sensor. Mater. Sci. Eng. C 2018, 90, 38-45. Available online: http:/ / www.sciencedirect.com/science/article/pii/S0928493117336950 (accessed on 11 June 2021). [CrossRef] [PubMed]

9. Muthuchamy, N.; Atchudan, R.; Edison, T.N.J.I.; Perumal, S.; Lee, Y.R. High-performance glucose biosensor based on green synthesized zinc oxide nanoparticle embedded nitrogen-doped carbon sheet. J. Electroanal. Chem. 2018, 816, 195-204. [CrossRef]

10. McCormick, W.; Muldoon, C.; McCrudden, D. Electrochemical flow injection analysis for the rapid determination of reducing sugars in potatoes. Food Chem. 2021, 340, 127919. Available online: http://www.sciencedirect.com/science/article/pii/S0308814 620317817 (accessed on 17 June 2021). [CrossRef]

11. Song, Y.-Y.; Zhang, D.; Gao, W.; Xia, X.-H. Nonenzymatic Glucose Detection by Using a Three-Dimensionally Ordered, Macroporous Platinum Template. Chem. A Eur. J 2005, 11, 2177-2182. [CrossRef]

12. Welch, C.M.; Compton, R.G. The use of nanoparticles in electroanalysis: A review. Anal. Bioanal. Chem. 2006, 384, 601-619. [CrossRef]

13. Chen, C.; Xie, Q.; Yang, D.; Xiao, H.; Fu, Y.; Tan, Y.; Yao, S. Recent advances in electrochemical glucose biosensors: A review. RSC Adv. 2013, 3, 4473-4491. [CrossRef]

14. McCormick, W.; McCrudden, D. Development of a highly nanoporous platinum screen-printed electrode and its application in glucose sensing. J. Electroanal. Chem. 2020, 860, 113912. Available online: http://www.sciencedirect.com/science/article/pii/S1 572665720300953 (accessed on 28 May 2021). [CrossRef]

15. Park, S.; Chung, T.D.; Kim, H.C. Nonenzymatic Glucose Detection Using Mesoporous Platinum. Anal. Chem. 2003, 75, 3046-3049. [CrossRef]

16. Lotfi, Z.; Gholivand, M.B.; Shamsipur, M. Introduction of a non-enzymatic glucose sensor based on a g-C3N4/NiO/CuO nanocomposite. Anal. Biochem 2020, 616, 114062. Available online: http://www.sciencedirect.com/science/article/pii/S0003269 720305947 (accessed on 27 April 2021). [CrossRef]

17. Espro, C.; Marini, S.; Giusi, D.; Ampelli, C.; Neri, G. Non-enzymatic screen printed sensor based on Cu2O nanocubes for glucose determination in bio-fermentation processes. J. Electroanal. Chem. 2020, 873, 114354. Available online: http:/ / www.sciencedirect. com/science/article/pii/S1572665720305816 (accessed on 24 May 2021). [CrossRef]

18. Shamsabadi, A.S.; Tavanai, H.; Ranjbar, M.; Farnood, A.; Bazarganipour, M. Electrochemical non-enzymatic sensing of glucose by gold nanoparticles incorporated graphene nanofibers. Mater. Today Commun. 2020, 24, 100963. Available online: http: //www.sciencedirect.com/science/article/pii/S2352492819314667 (accessed on 18 June 2021). [CrossRef]

19. Promsuwan, K.; Kachatong, N.; Limbut, W. Simple flow injection system for non-enzymatic glucose sensing based on an electrode modified with palladium nanoparticles-graphene nanoplatelets/mullti-walled carbon nanotubes. Electrochim. Acta 2019, 320, 134621. Available online: http:/ / www.sciencedirect.com/science/article/pii/S0013468619314690 (accessed on 21 March 2021). [CrossRef]

20. Khosroshahi, Z.; Karimzadeh, F.; Kharaziha, M.; Allafchian, A. A non-enzymatic sensor based on three-dimensional graphene foam decorated with $\mathrm{Cu}-\mathrm{xCu} 2 \mathrm{O}$ nanoparticles for electrochemical detection of glucose and its application in human serum. Mater. Sci. Eng. C 2020, 108, 110216. Available online: http:/ / www.sciencedirect.com/science/article/pii/S0928493119312391 (accessed on 29 June 2021). [CrossRef] [PubMed]

21. Ji, X.; Ren, J.; Ni, R.; Liu, X. A stable and controllable Prussian blue layer electrodeposited on self-assembled monolayers for constructing highly sensitive glucose biosensor. Analyst 2010, 135, 2092-2098. [CrossRef]

22. Chen, Y.; Liu, X.-M.; Wu, X.; Liu, X.-C.; Dong, W.-H.; Han, B.-K.; Du, X.; Zhang, C.; Zhang, Y.-Y.; Wang, H.-T.; et al. An array of poly-l-histidine functionalized multi-walled carbon nanotubes on 4-aminothiophenol self-assembled monolayer and the application for sensitively glucose sensing. Electrochim. Acta 2017, 258, 988-997. Available online: http:/ / www.sciencedirect. com/science/article/pii/S0013468617325124 (accessed on 6 April 2021). [CrossRef]

23. Lee, I.; Loew, N.; Tsugawa, W.; Ikebukuro, K.; Sode, K. Development of a third-generation glucose sensor based on the open circuit potential for continuous glucose monitoring. Biosens. Bioelectron. 2019, 124-125, 216-223. [CrossRef]

24. Thompson, W.R.; Cai, M.; Ho, M.; Pemberton, J.E. Hydrolysis and Condensation of Self-Assembled Monolayers of (3Mercaptopropyl)trimethoxysilane on Ag and Au Surfaces. Langmuir 1997, 13, 2291-2302. [CrossRef] 
25. Kloke, A.; Köhler, C.; Gerwig, R.; Zengerle, R.; Kerzenmacher, S. Cyclic Electrodeposition of PtCu Alloy: Facile Fabrication of Highly Porous Platinum Electrodes. Adv. Mater. 2012, 24, 2916-2921. [CrossRef] [PubMed]

26. Weremfo, A.; Fong, S.T.C.; Khan, A.; Hibbert, D.B.; Zhao, C. Electrochemically roughened nanoporous platinum electrodes for non-enzymatic glucose sensors. Electrochim Acta 2017, 231, 20-26. Available online: http://www.sciencedirect.com/science/ article/pii/S0013468617302682 (accessed on 9 June 2021). [CrossRef]

27. Trasatti, S.; Petri, A. Real Surface AREA Measurements IN ELECTROCHEMISTRY. Int. Union Pure Appl. Chem. 1991, 63, 711-734. [CrossRef]

28. Chou, C.-H.; Chen, J.-C.; Tai, C.-C.; Sun, I.-W.; Zen, J.-M. A Nonenzymatic Glucose Sensor Using Nanoporous Platinum Electrodes Prepared by Electrochemical Alloying/Dealloying in a Water-Insensitive Zinc Chloride-1-Ethyl-3-Methylimidazolium Chloride Ionic Liquid. Electroanalysis 2008, 20, 771-775. [CrossRef]

29. Yang, D.-Q.; Hennequin, B.; Sacher, E. XPS Demonstration of $\pi-\pi$ Interaction between Benzyl Mercaptan and Multiwalled Carbon Nanotubes and Their Use in the Adhesion of Pt Nanoparticles. Chem. Mater. 2006, 18, 5033-5038. [CrossRef]

30. Romanchenko, A.; Likhatski, M.; Mikhlin, Y. X-ray Photoelectron Spectroscopy (XPS) Study of the Products Formed on Sulfide Minerals Upon the Interaction with Aqueous Platinum (IV) Chloride Complexes. Minerals 2018, 8, 579. [CrossRef]

31. Gao, F.; Zhou, F.; Yao, Y.; Zhang, Y.; Du, L.; Geng, D.; Wang, P. Ordered assembly of platinum nanoparticles on carbon nanocubes and their application in the non-enzymatic sensing of glucose. J. Electroanal. Chem. 2017, 803, 165-172. [CrossRef]

32. Unmüssig, T.; Weltin, A.; Urban, S.; Daubinger, P.; Urban, G.A.; Kieninger, J. Non-enzymatic glucose sensing based on hierarchical platinum micro-/nanostructures. J. Electroanal. Chem. 2018, 816, 215-222. Available online: https://www.sciencedirect.com/ science/article/pii/S1572665718302364 (accessed on 20 August 2021). [CrossRef]

33. Lin, L.; Weng, S.; Zheng, Y.; Liu, X.; Ying, S.; Chen, F.; You, D. Bimetallic PtAu alloy nanomaterials for nonenzymatic selective glucose sensing at low potential. J. Electroanal. Chem. 2020, 865, 114147. [CrossRef]

34. Imran, H.; Vaishali, K.; Antony Francy, S.; Manikandan, P.N.; Dharuman, V. Platinum and zinc oxide modified carbon nitride electrode as non-enzymatic highly selective and reusable electrochemical diabetic sensor in human blood. Bioelectrochemistry 2021, 137, 107645. [CrossRef] [PubMed]

35. Sreekumar, A.; Navaneeth, P.; Suneesh, P.V.; Nair, B.G.; Babu, T.G.S. A graphite pencil electrode with electrodeposited Pt-CuO for nonenzymatic amperometric sensing of glucose over a wide linear response range. Mikrochim. Acta 2020, 187, 113. [CrossRef] [PubMed]

36. Li, R.; Deng, X.; Xia, L. Non-enzymatic sensor for determination of glucose based on PtNi nanoparticles decorated graphene. Sci. Rep. 2020, 10, 16788. [CrossRef]

37. Hu, Y.J.; Du, W.J.; Chen, C.Y. Fabrication of flower-shaped Pt-Au-graphene nanostructure and its application in electrochemical detection of glucose. Chin. J. Anal Chem. 2014, 42, 1240-1244. [CrossRef]

38. Dhara, K.; Stanley, J.; Ramachandran, T.; Nair, B.G.; Satheesh Babu, T.G. Pt-CuO nanoparticles decorated reduced graphene oxide for the fabrication of highly sensitive non-enzymatic disposable glucose sensor. Sens. Actuators B Chem. 2014, 195, 197-205. [CrossRef]

39. Remes, A.; Manea, F.; Motoc, S.; Baciu, A.; Szerb, E.I.; Gascon, J.; Gug, G. Highly Sensitive Non-Enzymatic Detection of Glucose at MWCNT-CuBTC Composite Electrode. Appl. Sci. 2020, 10, 8419. [CrossRef]

40. Ridhuan, N.S.; Abdul Razak, K.; Lockman, Z. Fabrication and Characterization of Glucose Biosensors by Using Hydrothermally Grown ZnO Nanorods. Sci. Rep. 2018, 8, 13722. [CrossRef]

41. Zhang, R.X.; Yang, P.; Zhang, Y.X. A novel high-sensitivity non-enzymatic glucose sensor via Cu2O@CuO@NiCo2O4 nanowires as catalyst. Mater. Lett. 2020, 272, 127850. Available online: https://www.sciencedirect.com/science/article/pii/S0167577X20305553 (accessed on 2 July 2021). [CrossRef]

42. Jang, K.; Park, K.R.; Kim, K.M.; Hyun, S.; Ahn, C.; Kim, J.C.; Lim, S.; Han, H.; Mhin, S. Electrochemical performance of the spinel NiCo2O4 based nanostructure synthesized by chemical bath method for glucose detection. Appl. Surf. Sci. 2021, 545, 148927. Available online: https://www.sciencedirect.com/science/article/pii/S0169433221000039 (accessed on 18 July 2021). [CrossRef]

43. Xu, J.; Gao, Z.; Dou, X.; Song, Y.-Y. Needle-like Co3O4 nanoarrays as a dual-responsive amperometric sensor for enzyme-free detection of glucose and phosphate anion. J. Electroanal. Chem. 2021, 897, 115605. Available online: https: / /www.sciencedirect. com/science/article/pii/S1572665721006317 (accessed on 18 July 2021). [CrossRef] 